Gohier B, Ferracci L, Surguladze SA, Lawrence E, Allain P, El-Hage W, Kefi MZ, Garre JB, Le Gall D. Cognitive inhibition and working memory in unipolar depression. Journal of Affective Disorders 2009;116(12):100-105. doi:10.1016/j.jad.2008.10.028

\title{
Cognitive inhibition and working memory in unipolar depression.
}

Benedicte Gohier(1), Laetitia Ferracci(2), Simon A. Surguladze(4), Emma Lawrence (4), Philippe Allain (2), Wissam El Hage(3), Mohamed Zied Kefi (2), Jean-Bernard Garre(1), Didier Le Gall(2)

(1)Department of psychiatry, University Hospital of Angers, F - 49033 Angers, France

(2)Laboratory of Psychology (UPRES EA 2646), University of Angers, France

(3)INSERM U930, Université François Rabelais, Clinique Psychiatrique Universitaire, CHRU de Tours

\begin{abstract}
Summary
Background. Over the past decade, evidence has accumulated to suggest that people suffering from Major Depressive Disorder (MDD) present impairment in attention, working memory, executive function, including cognitive inhibition, problem- and task-planning. The aim of the current study was to assess inhibitory mechanisms within working memory with emotionally neutral material in a group of patients suffering from MDD. We hypothesized that impairment in cognitive inhibition is global and not only due to the emotional valence of the stimuli employed for the tasks.

Methods. Twenty patients with MDD (DSM-IV) and 20 healthy controls were recruited. To assess cognitive inhibition, we used neutral material, in the form of the Prose Distraction Task (PDT) (Connelly SL, 1991), Trail Making Test (TMT), Modified Card Sorting Test (MCST), Rule Shift Cards (RSC), Stroop test and Hayling Sentence Completion test (HSC). The Modified 6 elements test, the Brixton Spatial Anticipation test, the dual task performance and the verbal fluencies test were also used to assess other executive functions such as flexibility, planning tasks and memory.
\end{abstract}

Results. Individuals with depression showed impairment in cognitive inhibition. They made more errors on the PDT, alongside slower response times. Slower response times were also observed on the Stroop, TMT and RSC. The MDD group made more errors in HSC and performed worse than controls in the semantic part of verbal fluency and Modified 6 elements tasks. The impairment of access function was significantly associated with the level of depression.

Conclusion. Depressed patients showed inability to inhibit neutral information access to working memory, restrain and delete irrelevant information. This impairment in cognitive inhibition could underlie cognitive slowness and attentional deficits in depression.

Key words. Cognitive inhibition, unipolar depression, working memory, emotionally neutral material

\section{Background}

With a lifetime prevalence estimated at $16 \%$, major depressive disorders (MDD) are a major public health issue. Fifty percent of depressed patients relapse within two years of recovery and over $80 \%$ experience more than one depressive episode in their life (Goeleven et al., 2006). Over the past decade, evidence has accumulated to suggest that people suffering from MDD display impairments in attention (Paelecke-Habermann et al., 2005; Watts and Sharrock, 1985), working memory (Rose and Ebmeier, 2006), executive function (Austin et al., 1999; Degl'Innocenti et al., 1998; Fossati et al., 2002 ; Landro et al., 2001 ; Purcell et al., 1997; Rogers et al., 2004), including cognitive inhibition (Moritz S, 2002), problem- and planning tasks (Fossati et al., 2002). 
In a recent review, Porter (Porter et al., 2007) suggested that three different factors may explain the origin of neuropsychological impairment in MDD: firstly, reduced motivation on tasks involving effortful processing, such as working memory, selective attention or executive function. Secondly, catastrophic responses to failure, for example in the task of the Tower of London (Elliott et al., 1997). Thirdly, attentional biases and interpretation differences for emotional information (Goeleven et al., 2006; Joormann and Gotlib, 2008; Surguladze et al., 2004).

Inhibition describes an active process that tempers unwanted stimuli (external or internal) that compete for processing resources in the context of a limited capacity system (Hascher and Zacks, 1988). Hasher and Zacks proposed that "central to the efficient operation of working memory... are inhibitory mechanisms which, when normally functioning, serve to limit entrance into working memory to information that is along the "goal path" of comprehension. Inhibitory mechanisms serve to restrict access to information that is relevant, delete information that is no longer relevant, and restrain production of strong but potentially incorrect retrieval of information from working memory (Hasher et al., 1999).

Studies exploring cognitive inhibition in MDD have employed either neutral or emotional stimuli. Thus, the authors using neutral stimuli (Degl'Innocenti et al., 1998; Murphy et al., 1999; Fossati et al., 2002; Moritz et al., 2002; Stordal et al., 2005; Markela-Lerenc et al., 2006; Erickson et al., 2005) found consistent impairments. However, each of these studies has used tasks that tap on just one aspect of inhibition i.e. access, delete or restraint.

In other studies, emotional material was used and showed also impairment in cognitive inhibition. Depressed patients showed reduced negative priming of sad facial expressions but intact negative priming of happy expressions (Goeleven et al., 2006). In this task, patients were asked to respond to a target stimulus while ignoring a simultaneously presented emotional stimulus that is clearly marked as to-be-ignored and irrelevant to the task (access function). Joormann \& Gotlib (2008) used also emotional material to explore the updating of the contents of working memory, in a modified Sternberg task. This task was used to explore the ability to remove irrelevant negative information from working memory (restraint function). They found that depressed patients showed greater intrusion effects than controls when presented with negative words and indicated also that increased interference for irrelevant negative material is associated with rumination.

The aim of the current study was to assess inhibitory mechanisms within working memory with neutral material in a population of patients suffering from MDD. We hypothesized that impairment in cognitive inhibition is global and not only due to the emotional valence of the stimuli using for the tasks. We used several different neutral tasks to explore the different processes involved in cognitive inhibition: the Prose Distraction Task (Connelly et al., 1991) to explore the access function, the Rule Shift Cards (Wilson et al., 1997) for the deletion function and the Stroop Test (Stroop, 1935) and the Hayling Sentence Completion Test (Burgess and Shallice, 1997) for the restraint function. For the deletion function, we also used the Trail Making Test (Test Individual Army, 1944) and the Modified Card Sorting Test (Nelson, 1976) to explore the shifting part of the central executive component of working memory.

\section{Methods}

\section{Participants}

Twenty inpatients with major depression (15 female and 5 male, age 18-55 years), were 
examined at the University Hospital of Angers, France. All patients met the DSM-IV criteria for major depression. Diagnoses were made using the MINI International Neuropsychiatric Interview (MINI) (Sheehan et al., 1998). The depressive symptomatology at the time of the assessment was evaluated using the 21-item Hamilton Depression Rating Scale (HDRS) (Hamilton, 1960). Patients were included only if the score was above a cut-off point of 26 which corresponds to a severe intensity of major depression. For 11 depressed patients, it was the first episode of depression, for 7 - the second episode and two of the patients had more than 3 episodes. None of the recurrent depression patients were resistant to a prior antidepressant treatment. At the time of assessment, they all have been already on antidepressant treatment (SSRI) which began on admission to the unit. All patients were tested in the first two days after their admission in the unit, so before the treatment's efficacy (HDRS>26). Participants with serious physical or neurological illness, a history of head injury, neurodegenerative disorder, substance abuse or dependence in the last year, mental retardation, ECT in the last year were excluded.

Twenty healthy comparison participants, without a psychiatric or neurological history, were also recruited. Patients and controls were all French native, with a mini-mental scale score > 27, matched for gender and number of years of education.

\section{Neuropsychological assessment}

The following tests were used:

1. Mini-Mental State Examination (Folstein et al., 1975)

2. Frontal executive functions:

$\checkmark$ Modified six elements test (Wilson et al., 1997). Within ten minutes, the subject is asked to do alternatively three different tasks, each one divided in two parts: describing an event, naming pictures and counting. They organize the time to do all the different tasks but never doing two parts of the same task successively.

$\checkmark$ Brixton Spatial Anticipation Test (Burgess and Shallice, 1997). A test booklet contains 56 pages, at each page there are 10 coloured and numbered disks arranged in two lines and five columns (5 circles per line). One of these disks is black, others are blue. This black disk logically changes his position from page to page. The subject is asked to guess the position of the black disk on the next page.

$\checkmark$ Dual-task Performance (Baddeley, 1996). In the first part, the subjects are asked to repeat series of numbers (single condition). In the second part, the subjects are asked to repeat series of number while they cross out cases printed on a page (double condition).

$\checkmark$ FAS verbal fluency test. This is a French version (Cardebat et al., 1990) of FAS task (Miller, 1984). Subjects are asked to give in two minutes as many as possible words beginning with the letter $\mathrm{P}$ (phonemic fluency) and in another two minutes the most names of animals, beginning with any letter (semantic fluency).

\section{Inhibition:}

$\checkmark$ Access function: Prose distraction task (Connelly et al., 1991): Participants were asked to read four different stories. There were four forms for each story: the first form was the original story (T1), printed in a standard font. The other forms were printed in standard and italic fonts, including distracting emotionally neutral words: semantically related distracting words in the second form (T2), neutral distracting words in the third form (T3) and non-words as distracting words in the fourth form (T4). Before beginning the task, participants were asked to read clearly the original form of the story and informed that in the other versions, the text was printed in standard and italic fonts, including distracting words; they were asked to read only the original version and ignore the distracting words. After each block, they answered to 5 
questions about the text, to test their comprehension.

$\checkmark$ Deletion function:

- Trail Making Test (Test Individual Army, 1944). In the part A, subjects are asked to link chronologically numbers from 1 to 25 . In the part B, they are asked to link alternatively and chronologically, numbers and letters from 1 to 13 and A to L (1A-2B...).

- The Modified Card Sorting Test (Nelson, 1976). In this task, subjects are asked to classify cards, differentiating by shape, colour or number of shape, with a logical rule. From time to time, they are asked to change the rule, e.g. choose colour instead of shape as a classification principle.

- Rule shift cards (Wilson et al., 1997). Twenty red or black cards are presented to subjects. In a first part, they are asked to say "yes" if the card is red or "no" if the card is black. In a second part, they are asked to say "yes" if the colour of card is the same as the previous card and "no" if the colour of card is different from the previous card.

Restraint function:

- Stroop test (Stroop, 1935). In the first part, subjects are asked to read words printed in black, all words naming colours. In the second part, the same words are printed in colour and subjects are asked to give the colour of the ink; the name of the colour corresponding to that of the word describing this colour. In the third part, subjects are asked to name the colour of the ink, which does not correspond to the word they are reading (e.g. the word "green" printed in blue).

- The Hayling Sentence Completion test (Burgess and Shallice, 1997): In the first condition (response initiation), subjects had to complete sentences with a word clearly suggested by the context, whereas in the second condition (response inhibition), subjects had to produce a word that made no sense in the context of the sentence.

\section{Results}

Statistical analyses

Patients and controls were compared for age, education level using $t$ test. Neuropsychological variables were assessed by MANOVA, with the MMSE score as a covariate. Because of the multiple testing, the significance value was determined at $\mathrm{p}<.001$. A correlation analysis was performed to examine the association between the different functions of cognitive inhibition and executive functions (the significant value was determined at $\mathrm{p}<.001$ ). Subsequently, a linear regression was performed to examine interaction between depression and the different functions of cognitive inhibition. Power calculations based on existing literature showed that we needed 12 subjects in each arm to 0.9 power with effect size of 0.4 .

\section{Group characteristics}

Twenty depressed patients, mean age \pm S.D. $=41.35 \pm 8.72$ years, mean years of education \pm S.D. $=13.12 \pm 1.49$ years were matched with 20 controls, mean age \pm S.D. $=38.4 \pm 5.23 y$, mean years of education \pm S.D. $=13.4 \pm 1.26 y$. The groups did not differ in age $(t=.97$, $\mathrm{df}=25, \mathrm{p}=.34)$ and years of education $(\mathrm{t}=-.5, \mathrm{df}=25, \mathrm{p}=.62)$. (Table 1$)$.

The Mini-Mental State score was higher than 27 for both groups: mean \pm S.D. $=28.06 \pm 1.64$ for depressed patients, mean \pm S.D. $=29 \pm .67$ for controls $(t=-2.09, \mathrm{df}=25, \mathrm{p}=.97)$.

In the depressed group, the Hamilton Depression Rating Scale (HDRS) mean score was $30.25, \mathrm{SD}=1.4$. 
Table 1: Neuropsychological performance in depressed patients and controls

\begin{tabular}{|c|c|c|c|c|c|c|c|}
\hline & \multicolumn{2}{|c|}{$\begin{array}{c}\text { Depressed patients } \\
\mathrm{n}=20\end{array}$} & \multicolumn{2}{|c|}{$\begin{array}{c}\text { Controls } \\
\mathrm{n}=20\end{array}$} & \multicolumn{3}{|c|}{ Student's $t$ test } \\
\hline & mean & SD & mean & SD & $\mathrm{t}$ & $\mathrm{df}$ & $\mathrm{p}$ \\
\hline Age & 41.35 & 8.72 & 38.4 & 5.23 & .97 & 25 & .34 \\
\hline Education & 13.12 & 1.49 & 13.4 & 1.26 & -.5 & 25 & .62 \\
\hline \multirow[t]{3}{*}{ MMS } & 28.06 & 1.64 & 29 & .67 & -2.09 & 25 & .97 \\
\hline & & & & & \multicolumn{3}{|c|}{ MANOVA } \\
\hline & & & & & $\mathrm{F}$ & df & $\mathrm{p}$ \\
\hline \multicolumn{8}{|l|}{$\begin{array}{l}\text { Access function } \\
\text { PDT : }\end{array}$} \\
\hline time $(\mathrm{s}) \mathrm{T} 1$ & 158.77 & 22.73 & 122.8 & 6.05 & 50.3 & {$[1,38]$} & $<.001^{*}$ \\
\hline time (s) $\mathrm{T} 2$ & 247.22 & 45.93 & 167.49 & 18.66 & 44.6 & {$[1,38]$} & $<.001^{*}$ \\
\hline time (s) T3 & 191.8 & 29.24 & 135.83 & 10.27 & 58.5 & {$[1,38]$} & $<.001^{*}$ \\
\hline time (s) $\mathrm{T} 4$ & 150.9 & 22.83 & 123.69 & 4.01 & 21.8 & {$[1,38]$} & $.001 *$ \\
\hline Semantic distractors $\mathrm{T} 2$ & 6.18 & 5.29 & 1.4 & .97 & 18.5 & {$[1,38]$} & $<.001 *$ \\
\hline Neutral distractors T3 & 1.06 & 1.39 & 0 & 0 & 14 & {$[1,38]$} & .006 \\
\hline Non-words T4 & .06 & .24 & 0 & 0 & .8 & {$[1,38]$} & .38 \\
\hline \multicolumn{8}{|l|}{ Deletion function } \\
\hline \multicolumn{8}{|l|}{ TMT : } \\
\hline Part A time (s) & 73.46 & 18.05 & 47.31 & 4.02 & 37.9 & {$[1,38]$} & $<.001 *$ \\
\hline Part B time (s) & 146.07 & 65.66 & 69.75 & 5.72 & 23.9 & {$[1,38]$} & $<.001 *$ \\
\hline Part A errors & 0 & 0 & 0.1 & 0.32 & .82 & {$[1,38]$} & .37 \\
\hline Part B errors & 0.24 & 0.56 & 0.4 & .52 & .55 & {$[1,38]$} & .46 \\
\hline \multicolumn{8}{|l|}{ MCST } \\
\hline Time (s) & 440.86 & 280.77 & 253.24 & 27.49 & 8.3 & {$[1,38]$} & .01 \\
\hline Trials & 5.29 & 1.4 & 6.2 & 0.57 & 9.6 & {$[1,38]$} & .004 \\
\hline Perseverative errors & 4.18 & 3.84 & 0.8 & 1.06 & 11.8 & {$[1,38]$} & $\leq .002$ \\
\hline \multicolumn{8}{|l|}{ RSC : } \\
\hline First rule: time (s) & 29.15 & 5.97 & 20.34 & 1.71 & 35.8 & {$[1,38]$} & $<.001 *$ \\
\hline Second rule: time (s) & 35.55 & 5.62 & 23.57 & 1.38 & 79.3 & {$[1,38]$} & $<.001 *$ \\
\hline Second rule: errors & 0.18 & 0.39 & 0.5 & 0.53 & 6.8 & {$[1,38]$} & .113 \\
\hline \multicolumn{8}{|l|}{ Restraint function } \\
\hline \multicolumn{8}{|l|}{ Stroop: } \\
\hline Time $(\mathrm{s})$ & 83.44 & 19.35 & 32.14 & 4.46 & 148.8 & {$[1,38]$} & $<.001 *$ \\
\hline Errors & 2.18 & 2.72 & 0.4 & 0.52 & 3.6 & {$[1,38]$} & .07 \\
\hline \multicolumn{8}{|l|}{ Hayling test } \\
\hline Section 1 time (s) & 11.84 & 1.74 & 10.54 & 1.07 & 7.9 & {$[1,38]$} & .01 \\
\hline Section 2 time (s) & 72.08 & 29.66 & 30.46 & 4.45 & 53.4 & {$[1,38]$} & $<.001 *$ \\
\hline Section 2 errors & 8.41 & 4.33 & 3.57 & 2.39 & 13.2 & {$[1,38]$} & $<.001 *$ \\
\hline \multicolumn{8}{|l|}{ Executive functions } \\
\hline 6 elements rank score & 4.76 & 0.75 & 6 & 0 & 16.5 & {$[1,38]$} & $<.001 *$ \\
\hline Brixton errors & 16.29 & 7.64 & 12 & 1.49 & 7 & {$[1,38]$} & .038 \\
\hline \multicolumn{8}{|l|}{ Baddeley } \\
\hline Single task sequences & 0.77 & 0.09 & 0.66 & 0.15 & 26.2 & {$[1,38]$} & $.001 *$ \\
\hline Double task sequences & 0.76 & 0.11 & 0.65 & 0.76 & 7.8 & {$[1,38]$} & $<.01$ \\
\hline \multicolumn{8}{|l|}{ Verbal fluency } \\
\hline phonemic & 17.12 & 5.02 & 20.1 & 1.93 & 3.2 & {$[1,38]$} & .08 \\
\hline semantic & 26.88 & 4.92 & 33.5 & 2.4 & 32.6 & {$[1,38]$} & $<.001 *$ \\
\hline
\end{tabular}

\footnotetext{
* significant ( $\leq .001)$; PDT=Prose Distraction Task, TMT=Trail Making Test, MCST= Modified Card Sorting Test, RSC=Rule Shift Cards.
} 


\section{Cognitive inhibition}

Access function

At the Prose Distraction Task, depressed patients read slower than controls in all subtests. There were significant differences in reading the original story $(\mathrm{T} 1)$ time $\mathrm{F}(1,38)=50.3$, $\mathrm{p}<.001$; T2 with semantic distractors: $\mathrm{F}(1,38)=44.6, \mathrm{p}<.001$; 33 with neutral distractors: $\mathrm{F}(1,38)=58.5, \mathrm{p}<.001 ; \mathrm{T} 4$ with non-words as distractors: $\mathrm{F}(1,38)=21.8, \mathrm{p}=.001$. Depressed patients made more errors in the following subtests: they read significantly more semantic distractors (T2) than the controls $\mathrm{F}(1,38)=18.5 ; \mathrm{p}<.001)$, but did not read more neutral distracting words $(\mathrm{T} 3)$ : $\mathrm{F}(1,38)=14.0 ; \mathrm{p}=.006)$ and not significantly more non-words (T4): $\mathrm{F}(1,38)=.8 ; \mathrm{p}=.38$. All of the distracting words were emotionally neutral (Figure 1)

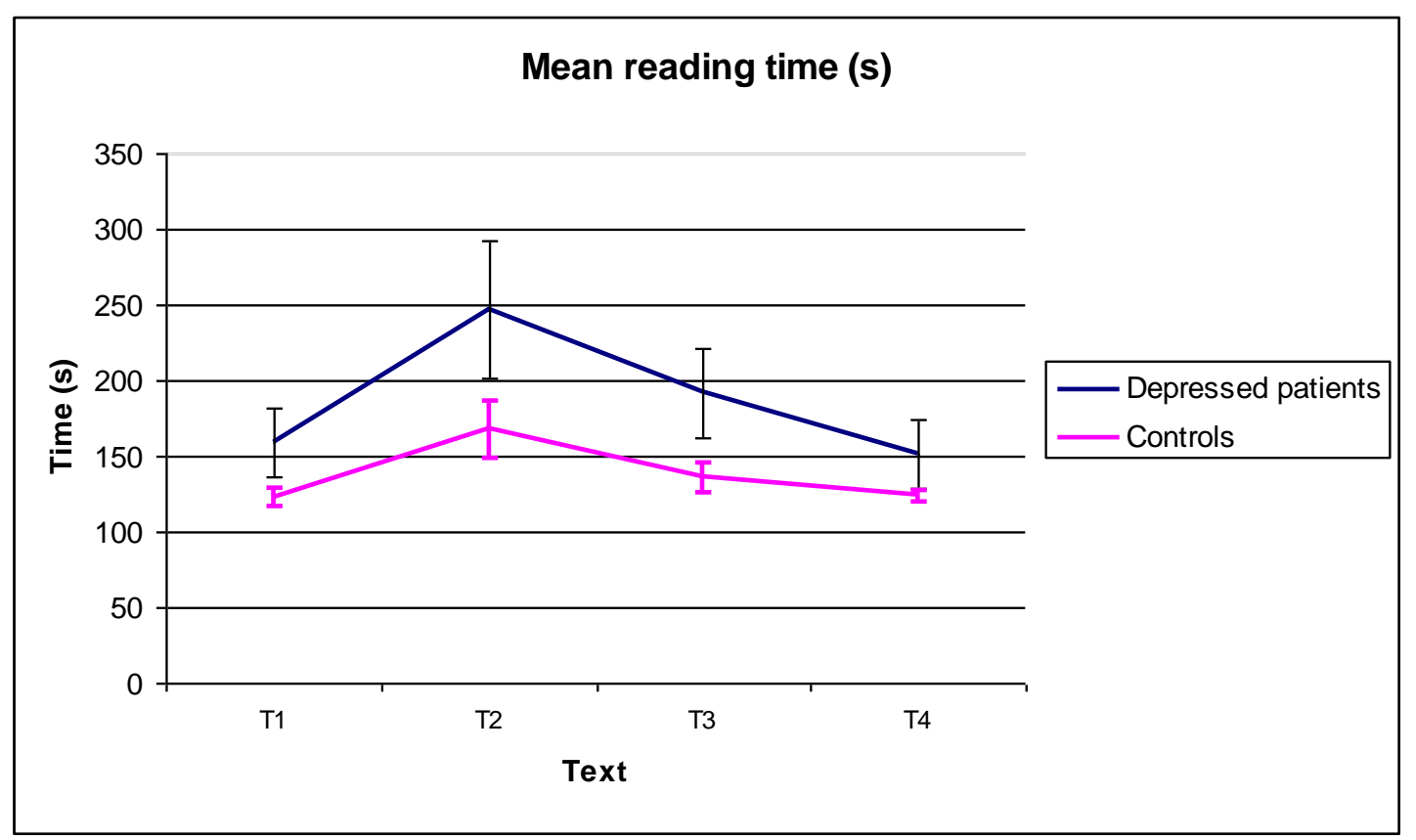

Fig 1. Prose Distraction Task, means for the reading time for each group and each kind of text (T1: original story, T2: text with semantic distracting words, T3: text with neutral distracting words, T4: text with distracting non-words).

Deletion function

Depressed patients were slower to complete both parts of the Trail Making Test (Part A: $\mathrm{F}(1,38)=37.9, \mathrm{p}<.001$; Part $\mathrm{B}: \mathrm{F}(1,38)=23.9, \mathrm{p}<.001)$ but did not make significantly more errors in Part A: $\mathrm{F}(1,38)=.82, \mathrm{p}=.37$; Part $\mathrm{B}: \mathrm{F}(1,38)=.55, \mathrm{p}=.46)$. There was no significant difference in the results at Modified Card Sorting Test with regard to time to execute the task $(\mathrm{F}[1,38]=8.3, \mathrm{p}=.01)$, the number of trials $(\mathrm{F}[1,38]=9.6, \mathrm{p}=.004)$, and perseverative errors $(\mathrm{F}[1,38]=11.8, \mathrm{p}<.002)$. In the rule shift cards, depressed patients took more time to execute the task (for the first rule: $F[1,38]=35.8, p<.001$ and the second rule: $F[1,38]=79.3$, $p<.001$ ). Neither group have made any errors in the first rule subtest, and the patients did not make significantly more errors than controls in the second rule subtest: $F(1,38)=6.8, p=.113)$.

\section{$\underline{\text { Restraint function }}$}

The time to execute the Stroop colour test was significantly longer in the depressed group $(F[1,38]=148.8, p<.001)$, with no significant difference in errors $(F[1,38]=3.6 ; p=.07)$. The performance in the second part of the Hayling Sentence Completion Test, was worse in patients, with longer time: $\mathrm{F}(1,38)=53.4, \mathrm{p}<.001$ and more errors: $\mathrm{F}(1,38)=13.2, \mathrm{p}<.001)$. 


\section{Executive functions}

A group difference was found in the Modified six elements test. The score, calculated by the number of series done minus the number of series without the rule, was significantly lower for depressed patients in comparison with the controls $(\mathrm{F}[1,38]=16.5, \mathrm{p}<.001)$. No significant differences were found in the Brixton test errors score $(F[1,38]=7.0, p=.038)$. In the Dual-task performance, depressed patients repeated less sequences both in the simple task $(\mathrm{F}[1,38]=26.2, \mathrm{p}<.001)$ but not in the dual task condition $(\mathrm{F}[1,38]=7.8, \mathrm{p}<.01)$. In depressed group verbal fluency was impaired significantly in semantic subtest: $F[1,38]=32.6, p<.001$ ), but not in phonemic $(\mathrm{F}[1,38]=3.2 ; \mathrm{p}=.08)$. (Table 1$)$

\section{Correlations}

We found positive correlations between measures of different functions:

1) between access and restraint functions: time of reading neutral distractors (PDT) and the number of errors at Stroop task $(\rho=.768, p<.001)$; number of non-words read (PDT) and time to execute part 2 of Hayling test $(\rho=.724, p=0.001)$

2) between access function and executive functions: number of semantic distractors read (PDT) and number of errors at Brixton test: $(\rho=.845, p<.001)$.

3) between deletion and restraint functions: time in TMT part A correlated with Stroop time (Pearson $\mathrm{r}=.48 ; \mathrm{p}=0.03$ ) and TMT part B correlated with time to execute part 2 of Hayling test (Pearson $\mathrm{r}=.50 ; \mathrm{p}=0.03$ ).

We found no correlation between access and deletion functions.

In the control group, we found no correlations either between the tests of different functions.

A linear regression was performed to examine whether any aspects of cognitive inhibition predicted the depressive state. In this analysis we entered the variables that have significantly differentiated the patients group from the controls. To avoid the problem of mutlicollinearity, we have chosen the variables belonging to the functions of access and deletion that were not correlated.

Step-wise linear regression analysis was performed with HDRS score as dependent variable and the following independent variables: PDT T1 (time), PDT T2 (errors and time), PDT T3 (time), PDT T4 (time), TMT A and B (time measure), Rule shift task (time for $1^{\text {st }}$ and $2^{\text {nd }}$ rules).

The analysis produced a significant ANOVA: $F(1,18)=8.0 ; p=0.01$. The most significant predictor of HDRS score was the PDT T2 time score which accounted for $31 \%$ of the variance (standardised beta $=.56 ; \mathrm{p}=0.01$ ).

\section{Discussion}

To summarize, our study demonstrated an impairment in patients with depression in all three aspects of inhibition process: access, restraint and deletion, along with preservation of some cognitive processes. These preserved processes were cognitive flexibility (measured by errors in TMT part A and part B, and MCST), deduction of rules (Brixton test) and restraint as measured by Stroop errors rate.

On the other hand, the following aspects of inhibition were impaired. In the Prose Distraction Task (tapping on access function), depressed patients showed difficulties when attempting to inhibit intrusion of irrelevant words in working memory, were reading more slowly and making more errors than the controls. Depressed patients showed an inability to restrain irrelevant information in the Hayling Sentence Task and performed slower in Stroop task. Regarding the deletion function, the depressed patients took more time in the Rule Shifting task and Trail Making Test.

These findings are comparable with other studies, using the same tasks with neutral stimuli: impairment in Trail Making (Austin et al., 1999; Moritz et al., 2002; Purcell et al., 1997), 
Stroop (Fossati et al., 2002 ; Markela-Lerenc et al., 2006; Stordal et al., 2005), Wisconsin Card Sorting tests performance has been previously found in MDD. However, this is the first study to show impairments in all three inhibition domains, using neutral material. Importantly, some executive functions were preserved in our patients - e.g., the patients were not significantly worse than the controls in Brixton test (error rate), Dual task (dual sequences) and FAS (phonemic fluency). This rules out a general impairment or apathy that could otherwise confound our results. We found positive correlations between the measures of different functions (access and restraint; deletion and restraint, access and executive) in patients, but not in the control group. This could mean that the 3 functions of cognitive inhibition are usually independent, but not in depression.

Our results could help in interpretation of underlying mechanisms of some of the symptoms pertinent to depression, in particular, cognitive slowness and the attentional deficit. In the Prose Distraction task, depressed patients spent more time in reading semantically related distracting words, even though these words were emotionally neutral. This particular aspect of inhibition (i.e., time to read the text with semantically related distractors) appeared to have the strongest association with the degree of depression.

According to the model of Hasher and Zacks, deletion function should be a second filter. But, in case of weak deletion function, irrelevant information like ruminations or negative thoughts are not deleted, saturating working memory. This could explain slowness of cognitive processes in MDD. We have not addressed the issue of ruminations in our study therefore these suggestions warrant further investigation.

It would be noteworthy to consider yet another aspect of MDD - that of attentional bias. Previous findings showed that depressed patients demonstrated failure to inhibit negative information presented as non-verbal (Goeleven et al., 2006; Surguladze et al., 2004) or verbal stimuli (Lau et al., 2007). Lau et al. (2007) showed that depressed patients read more slowly the stories containing negative distracting words vs. healthy controls, with an increase of frequency of negative thinking and a ruminative response style with the negative valence stories. This could be explained by the impairment in restraint function. Because of poor efficiency of restraint function, depressed patients seem to be relatively more susceptible to interference from irrelevant information. According to the model of Hasher and Zacks, impairment in restraint function could be reflected in a delay of the suppression of taskirrelevant mental representations with increased interference with task-relevant processing.

Limitations: all depressed patients were undergoing treatment (SSRI) at the time of assessment. Even though patients were assessed before the treatment efficacy (HADS > 26), it should be important to replicate these same results, using the same methods in a sample of unmedicated MDD patients.

\section{Conclusion}

The aim of this study was to explore the cognitive inhibition in people with major depressive disorder, with particular focus on the links between inhibition and working memory, using neutral material. We found that depressed patients showed inability to inhibit neutral information accessing working memory, delete irrelevant information and restrain strong but irrelevant information. One of the aspects of the inhibitory process (access function) showed significant association with the level of depression score. Future studies should include both emotional and neutral material to explore whether the emotional valence of the stimuli intensifies the impairment in cognitive inhibition in MDD.

\section{References}


Austin, M.P., Mitchell, P., Wilhelm, K., Parker, G., Hickie, I., Brodaty, H., Chan, J., Eyers, K., Milic, M., Hadzi-Pavlovic, D., 1999. Cognitive function in depression: a distinct pattern of frontal impairment in melancholia? Psychol Med. 29, 73-85.

Baddeley, A.D., 1996. Exploring the central executive. Q J Exp Psychol A 49 5-28.

Bearden, C.E., Glahn, D., Monkul, E.S., Barrett, J., Najt, P., Villarreal, V., Soares, J.C., 2006.

Patterns of memory impairment in bipolar disorder and unipolar major depression. Psychiatry Res 142, 139-150.

Beck, A., 1967. Depression: Causes and Treatment. Philadelphia.

Burgess, P., Shallice, T., 1997. The Hayling and Brixton Tests. Thames Valley Test Company.

Cardebat, D., Doyon, B., Puel, M., Goulet, P., Joanette, Y., 1990. Evocation lexicale formelle et sémantique chez des sujets normaux. Performances et dynamiques de la production en fonction du sexe, de l'âge et du niveau d'étude. Acta Neurologica Belgia 90, 207-217.

Connelly, S.L., Hasher, L., Zacks, RT., 1991. Age and reading: the impact of distraction. Psychol Aging 6, 533-541.

Degl'Innocenti, A., Agren, H., Backman, L., 1998. Executive deficits in major depression. Acta Psychiatr Scand 97, 182-188.

Elliott, R., Sahakian, B., Herrod, J.J., Robbins, T.W., Paykel, E.S., 1997. Abnormal response to negative feedback in unipolar depression: evidence for a diagnosis specific impairment. $\mathbf{J}$ Neurol Neurosurg Psychiatry. 63, 74-82.

Erickson, K., Drevets, W.C., Clark, L., Cannon D.M., Bain, E.E., Zarate C.A., Charney D.S., Sahakian, B.J., 2005. Mood-congruent bias in affective go/no-go performance of unmedicated patients with major depressive disorder. Am J Psychiatry 162, 2101-3.

Folstein M.F., Folstein, S.E., McHugh, P.R., 1975. Mini Mental State“: a practical method for grading the cognitive state of patients for the clinician. . J Psychiatr Res. 12, 189-198.

Fossati, P., Ergis, A., Allilaire, J.F., 2002 Executive functioning in unipolar depression: a review. . Encephale 28, 97-107.

Goeleven, E., De Raedt, R., Baert, S., Koster, E.H., 2006. Deficient inhibition of emotional information in depression. J Affect Disord. 93, 159-157.

Hamilton, M., 1960. A rating scale for depression. J Neurol Neurosurg Psychiatry 23, 56-62

Hascher, L., Zacks, R., 1988. Working memory, comprehension and aging:a review and a new review. The Psychology of Learning and Motivation 22, 193-225.

Hasher, L., Zacks, R., May, C.P., 1999. Inhibitory control circadian arousal, and age. In: Gopher D, K.A. (Ed.), Attention and performance. MIT Press, Cambridge, pp. 653-675.

Joormann, J., Gotlib, I., 2008. Updating the contents of working memory in depression: interference from irrelevant negative material. J Abnorm Psychol. 117, 182-192.

Landro, N.I., Stiles, T., Sletvold, H., 2001 Neuropsychological function in nonpsychotic unipolar major depression. Neuropsychiatry Neuropsychol Behav Neurol 14, 233-240.

Lau, M.A., Christensen, B., Hawley, L.L., Gemar, M.S., Segal, Z.V., 2007. Inhibitory deficits for negative information in persons with major depressive disorder. Psychol Med 37, 12491259.

Markela-Lerenc, J., Kaiser, S., Fiedler, P., Weisbrod ,M., Mundt, C., 2006. Stroop performance in depressive patients: a preliminary report. J Affect Disord. 94, 261-267.

Matt, G.E., Vazquez, C., Campbell, W.K., 1992. Mood-congruent recall of affectively toned stimuli: A meta-analytic review Clinical psychology review 12, 227-255.

Miller E (1984). Verbal fluency as a function of a measure of verbal intelligence and in relation to different types of cerebral pathology. British Journal of Clinical Psychology, 8: 385-394. 
Moritz, S., Birkner, C., Kloss, M., Jahn, H., Hand, I., Haasen, C., Krausz, M., 2002. Executive functioning in obsessive-compulsive disorder, unipolar depression, and schizophrenia. Arch Clin Neuropsychol 17, 477-483.

Murphy, F.C., Sahakian, B.J., Rubinsztein, J.S., Michael, A., Rogers, R.D., Robbins T.W., Paykel E.S., 1999. Emotional bias and inhibitory control processes in mania ans depression. Psychol Med 29, 1307-21.

Nelson, H., 1976. A modified card sorting test sensitive to frontal lobe defects. Cortex 12, 313-324.

Paelecke-Habermann, Y., Pohl, J., Leplow, B., 2005. Attention and executive functions in remitted major depression patients. J Affect Disord. 89, 125-135.

Porter, R.J., Bourke, C., Gallagher, P., 2007. Neuropsychological impairment in major depression: its nature, origin and clinical significance. Aust N Z J Psychiatry 41, 115-128.

Purcell, R., Maruff, P., Kyrios, M., Pantelis, C., 1997. Neuropsychological function in young patients with unipolar major depression. Psychol Med 27, 1277-1285.

Rogers, M.A., Kasai, K., Koji, M., Fukuda, R., Iwanami, A., Nakagome, K., Fukuda, M., Kato, N., 2004. Executive and prefrontal dysfunction in unipolar depression: a review of neuropsychological and imaging evidence. Neurosci Res 50, 1-11.

Rose, E.J., Ebmeier, K., 2006. Pattern of impaired working memory during major depression.. J Affect Disord. 90, 149-161.

Sheehan, D.V., Lecrubier, Y., Sheehan, K.H., Amorim, P., Janavs, J., Weiller, E., Hergueta, T., Baker, R. and Dunbar, G.C., 1998. The Mini-International Neuropsychiatric Interview (M.I.N.I.): The Development and Validation of a Structured Diagnostic Psychiatric Interview for DSM-IV and ICD-10. Journal of Clinical Psychiatry 59, 22-33.

Stordal, K.I., Lundervold, A., Mykletun, A., Asbjørnsen, A., Biringer, E., Egeland, J., Hammar, A., Landro, N.I., Roness, A., Rund, B.R., Sundet, K., Lund, A., 2005. Frequency and characteristics of recurrent major depressed patients with unimpaired executive functions. World J Biol Psychiatry 6, 36-44.

Stroop, J.R., 1935. Studies of interference in serial verbal reactions. Journal of Experimental Psychology 6, 643-661.

Surguladze, S.A., Young, A., Senior, C., Brebion, G., Travis, M.J., Phillips, M.L., 2004. Recognition accuracy and response bias to happy and sad facial expressions in patients with major depression. Neuropsychology 18, 212-218.

Test Individual Army, 1944. Manual of directions and scoring. Washington, DC : War department, Adjutant General's office.

Watts, F., Sharrock, R., 1985. Description and measurement of concentration problems in depressed patients. Psychol Med 15, 317-326.

Wilson, B.A., Evans, J., Alderman, N., Burgess, P.W., Emslie, H., 1997. Behavioural assessment of the dysexecutive syndrome. In: P, R. (Ed.), Methodology of frontal and executive functions. Psychology Press, United Kingdom, pp. 239-250. 